INDEPENDENT JOURNAL OF MANAGEMENT \& PRODUCTION (IJM\&P)

http://www.ijmp.jor.br

v. 9, n. 2, April - June 2018

ISSN: 2236-269X

DOI: 10.14807/ijmp.v9i2.674

\title{
HOW QUALITY INFLUENCES IN AGILITY, FLEXIBILITY, RESPONSIVENESS AND RESILIENCE IN SUPPLY CHAIN MANAGEMENT
}

Gilmar Lucio da Silva São Paulo State University, Campus Jaboticabal, Brazil E-mail: gilmar.silva@hotmail.com

Gustavo Rondina São Paulo State University, Campus Jaboticabal, Brazil E-mail: rondina.gustavo@gmail.com

Paloma Cardoso Figueiredo São Paulo State University, Campus Jaboticabal, Brazil E-mail: paloma_figueiredo@gmail.com

Glaucia Prates São Paulo State University, Campus Jaboticabal, Brazil E-mail: glaucia@itapeva.unesp.br

Antonio Francisco Savi São Paulo State University, Campus Jaboticabal, Brazil E-mail: savi@itapeva.unesp.br

Submission: $22 / 05 / 2017$ Revision: 08/06/2017 Accept: 30/11/2017

\section{ABSTRACT}

This article aims to present the quality and its direct influence on important characteristics that dominate the Design of the Supply Network, demonstrating the main aspects involved and the strategy developed to achieve a better performance. The study is based on a literature review and the main objective of this systematic review of the literature was to identify and classify all previous studies that examined some aspect of network analysis in the context of the supply chain since so far. It provides a detailed description of the most of the subject and contributes with a set of findings that capture the current state of art of the topic. Quality in the supply chain is a new subject and little studied, but it is observed that its influence is present in all sectors of the economy. 
INDEPENDENT JOURNAL OF MANAGEMENT \& PRODUCTION (IJM\&P)

http://www.ijmp.jor.br

v. 9, n. 2, April - June 2018

ISSN: 2236-269X

DOI: 10.14807/ijmp.v9i2.674

The classification of Supply Chains has been highlighted as a flow of materials and information that go from suppliers to final customers in the best possible way. With the development of a management that addresses the Supply Chain in a relevant way, the organization can achieve benefits that put it in a competitive position in the market.

Keywords: Quality, Supply Chain Management, Big Data, Agility, Flexibility, Responsiveness, Resilience.

\section{INTRODUCTION}

The rapid global development, in internal and external organizational context, leads to a continuous need to address the expectations of relevant interested parties.

Therefore, organizations and entities are permanently facing uncertainty and consequently new and diversified challenges day by day, suggesting pro-activity needs at the level of implementation regarding continuous improvements, better performance and innovations of organizational and operational processes as well as products with good expectations, sustainable business performance and excellence.

With a structured Supply chain is possible to achieve the creation of value in organization that depends on the ability to potentiate the continuous improvement and innovation of products and processes

Sometimes unplanned events occur in the supply chain network and it might affect the flow of material and components, here comes the strategy in supply chain management that will addresses the performance required by costumers.

\section{LITERATURE REVIEW}

Quality management has become a way to survive in the manufacturing sector, in fact in every sector, whether service, logistic, road building, or any other sector, and its importance is widely understood. Without a system in place to establish procedure, monitor progress, and evaluate performance, it is nearly impossible to consistently deliver a quality product to customers or prevent disruption risks (KIRAN, 2017).

Looking to serve customers, some companies have implemented tools that could help them to manage their supply chain. 
Evaluating the implementation of Quality in the supply chain management in Brazil, most of systems were developed based on in Total Quality Management, MSSs, Six sigma, ISO 9000 standard, etc..

These systems have been created to avoid or reduce the day to day problems that supply chain management faces.

One such system is Total Quality Management (TQM) which, together, Supply Chain Management are two of the important tools that manufacturing companies use to gain competitive advantage. Quality is an important factor in adding value to the process in production and delivery of the products along the supply chain.

One of the key players in the supply chain network (so important in achieving quality) is the supplier.

As mentioned by Kannan and Tan (2007), investigating the impact of quality management practices they observed that the quality of the supplies was directly related to higher level of quality conformance, reduced variation in quality performance and reduction of production costs and the certification of these suppliers is very important to achieve the performance required by consumers.

\subsection{Quality in Supply Chain Management}

Supply chain quality management has been received significant attention from the researcher in recent years. However, the knowledge about the effect of a manufacturer's design and capability of production is limited in this field (ZHANG et al., 2017), thus further study is required in this respect.

According Zhang et al. (2017) Supply Chain Integration is an extension of the coordination of the flow of materials and information to suppliers and end customers.

The supply chain quality integration is defined as the degree to which an organization's internal function and external supply chain partners strategically and operationally collaborate with each other to jointly manage inter and external organization quality-related relationship, communication, processes, etc. with the objective to achieve high level of quality-related performance at low costs. This integration include internal supplier and costumer quality integration, capturing both internal and external supply chain contexts (ZHANG et al., 2017). 
To understand each player in this study, each was defined for better understanding.

\subsection{Definitions}

\subsubsection{Supply Chain Management (SCM)}

Inquiring about the definition of Supply Chain Management were found some denominations. The definition adopted here is the one that Stock and Boyler (2009) suggest.

"SCM is the management of a network of relationships within a company and between independent organizations and business units that covers material suppliers, purchasing, production, facilities, logistics, marketing and related systems that facilitate the direct and inverse flow of materials, services, finances and information from the producer from the source to the end costumer with the benefits of adding value, maximizing profitability through efficient and achieving costumers satisfaction".

This definition covers a wide range of definitions that could express the state of art of this sector.

The definition of Supply chain we can assume is: a relationship between sectors of one company/organization/business unit through which, in addition to meeting customer needs, value is added to this organization.

\subsubsection{Agility}

According Lim, Mak and Zen (2017) and Chan et al. (2017), Supply Chain Agility is considered the most critical success factor in our actual competitive market because it brings quick response and short lead time. It enables the members firms to be more sensitive regarding the market with capacity to respond rapidly to the changes, being able to synchronize supply with demand and to achieve shorter cycle times. Another characteristic is the capability to rapidly realign the network and its operations to meet the highly dynamic customer requirements.

\subsubsection{Flexibility}

Strategic flexibility and manufacturing flexibility are the critical antecedents to supply chain agility. Furthermore, supply chain agility, strategic flexibility and manufacturing flexibility are key factors in the company's performance. Flexibility 
consists of responding to customers' orders by dynamically adjusting network operations and this is essential for success. It is agreed that the organization flexibility is one of the most important factors to achieve superior supply chain agility (CHAIN et al., 2017).

\subsubsection{Responsiveness}

In recent years, a considerable number of companies have adopted responsiveness goals while design their supply chain network. According to Fattahi, Govindan and Keyvanshokooh (2017) a responsive supply chain could adapt itself to the consumers' needs alteration and changes in the target market.

Responsiveness to customers and market is an indispensable requirement for all industries, organization or business unities (CHAIN et al., 2017).

In fact, it is a key factor to avoid delay in the delivery, and specific in a logistics network, should be considered an important factor in the design of the distribution system network. A queuing system is known as the main tools for managing congestion and improving responsiveness in logistics systems. Many efforts have been made to show the validity of queuing systems to calculate waiting times and improve network responsiveness. Therefore, the implementation of queuing systems can be useful to solve the problems with longer waiting times and the delay in deliveries (ZHALECHIAN et al., 2017).

\subsubsection{Resilience}

According Bruijn et al. (2017) resilience is an ambiguous concept and could be interpreted differently by different persons. We have five key definitions for resilience to deal with extreme weather events, and these key definitions can be translated into five practical principles of resilience to support disaster risk reduction decisions and rules. The principles are: encourage taking an approach of this system, considering beyond-design events, assuring that the system can remain working under extreme events, considering system response / recovery, and including gradual future changes. Applying these principles in practice will aid in developing strategies and designing adaptive pathways into the future which will make the system more resilient to extreme weather events.

In other definition, resilience is the ability to recover quickly to the same natural state (COLLINS, 2014). 


\subsubsection{Big Data}

The demand for data analysis is growing day by day and is necessary to find technologies that could work with this situation, the huge mass of information generated is very important for some entities

Currently, the volume of this data is doubling every year, due the historic data that the organizations are storing and the time that they are storing. Example: Social media provide huge amount of text data (Facebook has more than 901 million active users generating social interaction data); Radio-Frequency Identification (RFID) systems generate up to 1,000 times the data of conventional bar code systems. The variety of this data and unstructured forms (images, audio, tweets, text messages, server logs and so on) is huge as well, it came in all types of formats, from a standard production system or transaction database to OLAP (Online Analytics Processing) cubes, emails, stock or financial data to a huge non-numerical data.

The Speed of this data is produced and how fast it must be processed to meet required or demands, is another important aspect. (MICHALIK; STOFA; ZOLOTOVÁ, 2014).

According Lee (2017); Herschel and Miori, (2017); Michalik, Stofa and Zolotová (2014), Big Data is a digital phenomenon and technology paradigm that enables the collection and use of massive amounts of data derived from both man and machine. This data is characterized in terms of its volume, variety, velocity, veracity, variability, and its complexity. It allows firms to rapidly capture, analyze, and exploit information.

Big data is envisioned as a game changer capable of revolutionizing the way businesses operate in many industries.

According SAS Company, the importance of Big Data is what you do with the great volume of data that you have.

Is possible to analyze data from any source to find answers that allow cost reduction, time reduction, new product development and optimized offerings and smarter decisions. When you combine big data with high-powered analytics, you can perform business-related tasks such as: 
- Determine the root cause of near-real-time faults, problems, and defects;

- Generate coupons at the point of sale based on customers' buying habits;

- Recalculate entire risk portfolios, in a matter of minutes;

- Detect fraudulent behavior before it affects your organization.

One important action that companies need to do is to prevent risks in the supply chain network, it is critical to the success of the company.

\subsection{Risks in Supply Chain Network}

In actual days, some companies operating within highly integrated supply chains are increasingly vulnerable to disruptions caused by natural and man-made disasters. These disruptions born in recent events, such as the 2010 devastating earthquake in Haiti that victimized thousands of people, the 2011 floods in Thailand with economic costs estimated around US\$450bn and the 2013 typhoon in the Philippines that left massive property destruction. Risks and unpredictable events exist during each stage of activities necessary to acquire products and services to deliver output to customers. Unintended or unforeseen disruptions can occur during purchasing, manufacturing or even delivery, which adversely affect the ability of the company to attend their customers. The effect of risks and uncertainty must be anticipated by mitigation efforts aimed at maintaining overall business continuity (KURVIAWAN et al., 2017)

These events are called by disruption risks.

\subsubsection{Disruption risk}

The disruption risk have been studied by professional and researchers of the area due to their impacts as long lead-times, stock-outs, inability to meet costumers demand resulting in costs increase.

Despite these problems, the natural disruptions as floods, earthquakes, economic crisis and terrorist attacks have received more attention by the scholars (FATTAHI; GOVINDAN; KEYVANSHOKOOH, 2017).

The first strategic step to avoid this kind of risk is to identify them and determine all the risks that could happen in the process, understand the likelihood 
and extend of the most significant risks and develop risk mitigation strategies that will guide the management to act properly (FENG; JUN-QI; DAO-MING, 2010).

\subsection{Strategies to improve the Quality in Supply Chain}

To have a resilient network under disruption events, some companies use mitigation strategies.

Mitigation strategies are preventive activities performed before occurrence of a possible disruption, irrespective if it happens or not. But if and when it occurs contingency strategies are adopted to reinstate the supply chain to it previous condition (FATTAHI; GOVINDAN; KEYVANSHOKOOH, 2017).

One of the strategies that companies could use is the implementation of a radio frequency identification (RFID) system in your process.

RFID technology holds the promises of revolutionizing supply chain management by providing automatic real-time Supply Chain visibility. Great retailers gave RFID impetus by mandating that their top suppliers tag cases and pallets with RFID in 2005. Wal-Mart subsequently reported that this reduced out-of-stocks by $21 \%$, achieved up to three times faster replenishment of out-of-stock orders and reduced manual orders. RFID adoption also helped Metro Group to realize significant time and labor cost savings (LEUNG; CHEUNG; CHU, 2014).

Despite the complexity of the supply chain network model, it specific context depends entirely on its members. In order to succeed in the market, companies must develop strategies (CHANG; CHIANG; PAI, 2012).

\subsection{Purpose of the research}

The supply chain needs to be able to respond quickly, organizational flexibility, avoid delays in delivery, and the ability to recover quickly. The objective of this study is to show how quality directly influences these items, which are the main principles that structure the supply chain management..

\section{METHODOLOGY}

According to Fink (2009), a literary review is a clear, structured and reproducible research to identify, evaluate and interpret the existing body of documents evidenced therein. The objectives of a literature review are generally two: 
- First: summarize research by identifying patterns, approaches, and recurring issues;

- Second: identify the concept of the field for the development of theory.

The literature review process was carried out following the assumptions of Levy and Ellis (2006), that is, selecting, and understanding, applying, analyzing, synthesizing and evaluating the literature. The practice of this activity guarantees a structured and reliable review of the literature and ensures the objectivity of the research process. (FORMENTINI; ROMANO, 2016).

The adopted methodology for this work has been the descriptive bibliographic research. This research project is appropriate to provide a detailed description of the most important aspects of the subject matter, taking into account specific points of view and different perspectives (AGIG; NIEMANN; KOTZÉ, 2016).

In order to address the research questions, a thorough review was carried out on the literature on the supply chain with the objective of sustainability about an organization applying knowledge.

To elaborate these research methods, it will use:

- The articles contributing significantly in the domain of supply chain resilience were selected for final review and various issues were identified.

- The research methodology it will be characterized as a bibliographic research, since it explains the problematic approach from theoretical references.

- The keywords will be divided into categories: related words about supply chain design; related words about quality of supply chain network and related words about agility, flexibility, responsiveness, resilience as the way to improve the chain and the process;

When the content of the analysis was being prepared, the purpose was to select the documents and at least answer:

- In what ways could the supply chain achieve quality from principles of influence: agility, flexibility, responsiveness, resilience, and quality?

- What would be the ideal design to achieve such influencing principles? 
- How do the market and the organization behave in the face of such requirements?

The primary goal of this systematic literature review was to identify and classify all previous studies that examined some aspect of network analysis in the supply chain context since 2016. Articles on supply chains were chosen using a knowledge network and several academic databases commonly used in these surveys were also used including Scopus of Coordenação de Aperfeiçoamento de Pessoal de Nível Superior - CAPES (from Brazil), Web of Science, and Google Scholar.

It was used a combination of search keywords: "network design", "quality of supply chain network" "network design" "supply network," "network structure," "agility, flexibility, responsiveness, resilience in supply chain " "network dynamics," and "network strategy." These keywords were chosen because of the relationship each one has with Quality.

The key reasoning was that the unit of analysis had to be an organization, firm, or business unit. As a result, did not include interpersonal network studies. Next, we manually examined the full text of each of the articles and discarded studies that did not specifically examine some aspect of SCSs. Lastly, we excluded conference proceedings, working papers, and theses in concordance to previous literature reviews (GUNASEKARAN; NGAI, 2005).

It was classified studies according to their primary research focus, as it relates to the three structural and behavioral aspects of interfirms relationships that affect Supply Chain design and performance of organization:

- The Supply Chain Design dynamics: system behavior;

- The Supply Chain Design structure: system behavior;

- The Supply Chain Design strategy: system policy and control;

The coding process consisted of both authors independently assessing and assigning primary research method and research theme to each article. Differences were resolved through discussion (BELLAMY; BASOLE, 2012).

The main challenge is how to address the different and major weaknesses and differentiations of networks and their analysis on this. The literature can be 
INDEPENDENT JOURNAL OF MANAGEMENT \& PRODUCTION (IJM\&P)

http://www.ijmp.jor.br

v. 9, n. 2, April - June 2018

ISSN: 2236-269X

DOI: 10.14807/ijmp.v9i2.674

classified based on the operational processes and the supply chain of agricultural products, processing, manufacturing, planning, control, design, accounting, perishable logistics, chain management, safety and food quality, among others. Based on measures of performance, quality and service flexibility, these indicators can be perceived (MAHAJAN; GARG; SHARMA, 2017).

\section{CONCLUSION AND RECOMMENDATION}

The objective of this study is to show how the quality influences directly in this items that are the main principles that structures a supply chain management. After discussion about these principles it arrived that the Supply Chain is a strategic point in the life of any organization that thinks about the future. There is no way to eliminate good management of the supply chain of organization that seeks the satisfaction of the clients in full way as objective, and also, one can generate competitive strategies with the adoption of the chain management.

With chain management companies can achieve the much-desired value added in their services and products, as well as directly influence the quality of these services. Also in this sense, the chain provides improvements and advantages in the processes and products, as well as avoids the rupture with the proper mitigation of risk.

Quality in the supply chain is a new subject and little studied, but it is observed that its influence is present in all sectors of the economy. Was highlighted the classification of Supply Chains as a flow of materials and information that go from suppliers to end customers in the best possible way.

In order to achieve quality in the Supply Chain, it is necessary to develop a series of attributes, tools and strategies in the organization.

With the development of a management that addresses the Supply Chain in a relevant way, the organization can achieve benefits that put it in a competitive position in the market. The agility in the chain enables the service of dynamic customers and gives a rapid response to the changes, synchronizing supply and demand with the purpose of generating shorter cycles.

Strategic flexibility is a key part of achieving the agility mentioned above, although production flexibility is essential in the eyes of the Supply Chain. Not only flexibility and agility as a focus in the search for the quality of the chain suffice, but 
INDEPENDENT JOURNAL OF MANAGEMENT \& PRODUCTION (IJM\&P)

http://www.ijmp.jor.br

v. 9, n. 2, April - June 2018

ISSN: 2236-269X

DOI: 10.14807/ijmp.v9i2.674

rather the importance of receptivity as the organization's responsiveness to the client stands out. Supply Chain management is efficient in the sense of adding value to the service or product and also in processes, maximizing profitability and achieving customer satisfaction with greater quality and agility.

The mitigation of the risk of rupture is something seriously treated in the chains, because with natural disasters companies must have plans to decrease or avoid the breakdown of the supply of their products or services to the customers. To avoid the risk of supply disruption caused by unplanned events and to prevent it from affecting the flow of materials, the organization must have resilience in order to develop rapid recovery capacity for the natural state.

Organizations can use multiple systems to manage their chains, avoiding or reducing the problem journey. The systems cited in the work, MSSs, Six Sigma, ISO 9000 and T.Q.M enable the reduction of variation in quality performance, such as higher level of conformity and reduction in production costs.

As recommendation to improve this job is suggested to researchers a deep investigation in possible risks (not mentioned here) that Supply Chain could face and how to mitigate that, because as the technology is perfecting every day, new types of risks could emerging.

\section{ACKNOWLEDGEMENT}

Special thanks to UNESP - Universidade Estadual Paulista Julio de Mesquita Filho - Campus Jaboticabal - São Paulo - BRAZIL, to support this job and to all the coordination team of Professional Master Degree in Administration for the orientation and conduction.

\section{REFERENCES}

AGIG, A.; NIEMMAN, W.; KOTZÉ, T. (2016) Supply chain design approaches for supply chain resilience: A qualitative study of South African fast moving consumer goods grocery manufacturers. Journal of Transport and Supply Chain Management, n. 15.

BELLAMY, M. A.; BASOLE, R. C. (2012) Network analysis of supply chain systems: A systematic review and future research.

BRUIJN, K.; BUURMAN. J.; MENS, M.; DAHM, R.; KLIJN, F. (2017) Resilience in practice: Five principles to enable societies to cope with extreme weather events.

Environmental Sciences \& Police, v. 70, p. 21-30. 
INDEPENDENT JOURNAL OF MANAGEMENT \& PRODUCTION (IJM\&P)

http://www.ijmp.jor.br

v. 9, n. 2, April - June 2018

ISSN: 2236-269X

DOI: 10.14807/ijmp.v9i2.674

CHAN, A. T. L.; NGAI, E. W. T.; MOON, K. K. L. (2017) The effects of strategic and manufacturing flexibilities and supply chain agility on firm performance in the fashion industry. European Journal of Operational Research. Elsevier, v. 259, n. 2, p. 486-499.

CHENG, W. C.; CHIANG, D. M.; PAI, F. Y. (2012) Cooperative strategy in supply chain networks. Industrial Market Management. Elsevier, v. 41, n. 7, p. 1114-1124

COLLINS ENGLISH DICTIONARY (2014) Complete and Unabridged, 12th Ed. (1991, 1994, 1998, 2000, 2003, 2006, 2007, 2009, 2011, 2014). Retrieved April 15 2017 from http://www.thefreedictionary.com/resilience.

FATTAHI, M.; GOVINDAN, K.; KEYVANSHOKOOH, E. (2017) Responsive and resilient supply chain network design under operation and disruption risks with delivery lead-time sensitive costumers. ELSEVIER. Transportation Research Part E: Logistics and Transportation Review, v. 101, p. 176-200.

FENG, L.; JUN-QI, H.; DAO-MING, X. (2010) Managing disruption risks in supply chain. Emergency Management and Management Sciences (ICEMMS). IEEE International Conference.

FINK, A. (2009) Conducting Research Literature Reviews. Los Angeles: Internet to Paper.

FOMENTINI, M.; ROMANO, P. (2016) Towards supply chain collaboration in B2B pricing: A critical literature review and research agenda. Udine: International Journal of Operations \& Production Management.

HERSCHEL, R.; MIORI, V. M. (2017) Ethics \& Big Data. Technology in Society. Elsevier, v. 49, p. 31-36.

KANNAN, V. R.; TAN, K. C. (2007) The impact of operational quality: a supply chain view. Supply Chain Management: An International Journal, v. 12, n. 1, p.14-19, doi: 10.1108/13598540710724356

KIRAN, D. R. (2017) Chapter 34. ISO 9001 Quality Systems. Total Quality Management Key Concepts and Case Studies. Elsevier, p. 471-486.

KURNIAWAN, R.; ZAILANI, H. S.; IRANMANESH, M.; RAJAGOPAL, R. (2017) The effects of vulnerability mitigation strategies on supply chain effectiveness: risk culture as moderator. Supply Chain Management: An International Journal, v. 22, n. 1, p.1-15, doi: 10.1108/SCM-12-2015-0482.

LEE, I. (2017) Big data: dimensions, evolution, pacts and challenges. Business Orizons. Elsevier, v. 60, n. 3, p. 293-303.

LEUNG, J.; CHEUNG, W.; CHU, SUNG-CHI. (2014) Aligning RFID applications with supply chain strategies. Information \& Management. Elsevier, p. 260-269.

LIM, M. K.; MAK, H.Y.; SHEN, Z. J. M. (2017) Agility and Proximity Considerations in Supply Chain Design. Management Science, v. 63, n. 4, p. 1026-1041. http://dx.doi.org/10.1287/mnsc.2015.2380

MAHAJAN, R.; GARG, S.; SHARMA, P. (2017) Processed food supply chain: a framework for literature review. Gurgaon: Journal of Advances in Management Research.

MICHALIK, P.; STOFA, J.; ZOLOTOVÁ, I. (2017) Concept Definition for Big Data Architecture in the Education System. SAMI 2014. IEEE 12th International 
Symposium on Applied Machine Intelligence and Informatics. Retrieved April, 30. 2017 from http://ieeexplore.ieee.org.ez87.periodicos.capes.gov.br/stamp/ stamp.jsp?arnumber $=6822433$.

OFFICIAL WEBPAGE OF SAS COMPANY: http://www.sas.com/big-data/

RATH, R. C.; HOTA, N. R.; MAHARANA, H. S.; PATEL, S. K. (2014) An Analysis of Power Supply Design in Networking Systems on the Practices of Supply Chain Management. International Journal of Business and Economics Research. Special Issue: Supply Chain Management: Its Theory and Applications, v. 3, n. 6-1, p. 81-86, doi: 10.11648/j.ijber.s.2014030601.22.

STOCK, J. R.; BOYER, S. L. (2009). Developing a consensus definition of supply chain management: a qualitative study. International Journal of Physical Distribution Logistics Management, v. 39, n. 8, p. 690-711.

ZHALECHIA, M.; TAVAKKOLI-MOGHADDAM, R.; RAHIMI, Y. (2017) A selfadaptive evolutionary algorithm for a fuzzy multi-objective hub location problem: An integration of responsiveness and social responsibility. Engineering Application of Artificial Intelligence. Elsevier, v. 62, p.1-16.

ZHANG. M.; GUO, H.; HUO, B.; ZHAO, X.; HUANG. J. (2017) Linking Supply chain Quality integration with mass customization and product modulatory. International Journal of Production Economics. Elsevier. 